\title{
Assessing Self-Reported Interprofessional Competency in Health- Care Education: Impact of New Curriculum
}

\author{
Anthony Goreczny \\ Chatham University, goreczny@chatham.edu \\ Melissa L. Bednarek \\ Chatham University, mbednarek@chatham.edu \\ Susan R. Hawkins \\ Chatham University, hawkins@chatham.edu \\ Mark L. Hertweck \\ Chatham University, Mark.Hertweck@va.gov \\ Jodi Schreiber \\ Chatham University, jschreiber1@chatham.edu
}

See next page for additional authors

Follow this and additional works at: https://nsuworks.nova.edu/ijahsp

Part of the Medicine and Health Sciences Commons

\section{Recommended Citation}

Goreczny A, Bednarek ML, Hawkins SR, Hertweck ML, Schreiber J, Sterrett SE. Assessing Self-Reported Interprofessional Competency in Health-Care Education: Impact of New Curriculum. The Internet Journal of Allied Health Sciences and Practice. 2016 Jan 01;14(3), Article 11.

This Manuscript is brought to you for free and open access by the College of Health Care Sciences at NSUWorks. It has been accepted for inclusion in Internet Journal of Allied Health Sciences and Practice by an authorized editor of NSUWorks. For more information, please contact nsuworks@nova.edu. 


\title{
Assessing Self-Reported Interprofessional Competency in Health-Care Education: Impact of New Curriculum
}

\begin{abstract}
Purpose: The Interprofessional Education Collaborative Expert Panel (IPEC) has identified four competencies essential for interprofessional functioning in the health professions. Those four competencies are (a) values/ethics for interprofessional practice, (b) roles/responsibilities, (c) interprofessional communication, and (d) teams and teamwork. Design of effective curricula to develop competence in these skills will improve interprofessional functioning in healthcare. The purpose of this study at a small northeastern university was to examine impact of a small group interprofessional education (IPE) curriculum on student awareness of one of the competencies, understanding roles and responsibilities. Methods: The quantitative study data consisted of student completion of a 13-item selfreport questionnaire based on the four competencies of IPE after participating in two interprofessional events in the same semester (one large group introductory event and one small group case event). Students were enrolled in professional educational programs, including counseling psychology, nursing, occupational therapy, physical therapy, and physician assistant. Students were divided into groups of 8-10 students from participating academic programs forming interprofessional groups. They completed a 13-item self-report questionnaire based on the four competencies after each of the two events. Results: Results of Multivariate Analysis of Variance (MANOVA) revealed a significant difference between the first and second events, multivariate $F(13,476)=24.61, p=.000$. Results of univariate ANOVAs revealed significant differences for each variable, with scores from the case study session higher on each item than scores for the opening event. Factor analysis of data from the opening event yielded a single factor, which accounted for $63.4 \%$ of the variance in the scale. Factor analysis of data from the small group case event also yielded a single factor accounting for $65.9 \%$ of scale variance. Cronbach's alpha revealed a very high internal consistency of .951 and.952, for the two events respectively. Conclusions: IPE events can positively increase self-report measures of IPE competencies. The assessment tool used may have measured one overarching construct of collaboration. The tool represents an initial effort toward measurement of each of the four specific competencies, an area in need of refinement. This study demonstrated impact of IPE events housed within an IPE curriculum.
\end{abstract}

\section{Author Bio(s)}

Anthony Goreczny, PhD, is a Professor in psychology at Chatham University in Pittsburgh, PA.

Melissa L. Bednarek, PT, DPT, PhD, is an assistant professor in Physical Therapy at Chatham University.

Susan R. Hawkins, MSEd, PA-C, is an Associate Professor and PBL Coordinator in the Physician Assistant program at Chatham University.

Mark L. Hertweck, MA, PA-C, is an Associate Professor and Community Development Coordinator in the Physician Assistant program at Chatham University.

Jodi Schreiber, OTD, OTR/L, is an Assistant Professor in Occupational Therapy at Chatham University.

Susan E. Sterrett, EdD, RN, is an Assistant Professor of Nursing at Chatham University.

\section{Authors}

Anthony Goreczny, Melissa L. Bednarek, Susan R. Hawkins, Mark L. Hertweck, Jodi Schreiber, and Susan E. Sterrett 


\title{
TIAHSP

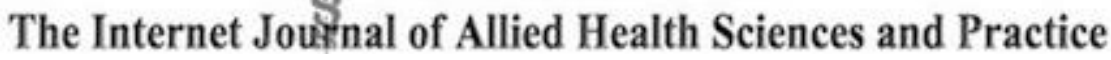

Dedicated to allied health professional practice and education

Vol. 14 No. 3 ISSN 1540-580X

\section{Assessing Self-Reported Interprofessional Competency in Health-Care Education: Impact of New Curriculum}

\author{
Anthony Goreczny, $\mathrm{PhD}$ \\ Melissa L. Bednarek, PT, DPT, PhD \\ Susan R. Hawkins MSEd, PA-C \\ Mark L. Hertweck MA, PA-C \\ Jodi Schreiber, OTD, OTR/L \\ Susan E. Sterrett, EdD, RN \\ Chatham University \\ United States
}

\begin{abstract}
Purpose: The Interprofessional Education Collaborative Expert Panel (IPEC) has identified four competencies essential for interprofessional functioning in the health professions. Those four competencies are a) values/ethics for interprofessional practice, b) roles/responsibilities, c) interprofessional communication, and d) teams and teamwork. Design of effective curricula to develop competence in these skills will improve interprofessional functioning in healthcare. The purpose of this study was to examine impact of a small group interprofessional education (IPE) curriculum on student awareness of one of the competencies, understanding roles and responsibilities. Methods: Students enrolled in professional educations curriculums including counseling psychology, nursing, occupational therapy, physical therapy, and physician assistant programs participated in two interprofessional events in the same semester (one large group introductory event and one small group case event). Students were divided into groups of 8 to 10 students from participating academic programs forming interprofessional groups. They completed a 13-item self-report questionnaire based on the four competencies after each of the two interprofessional events. Results: Results of Multivariate Analysis of Variance (MANOVA) revealed a significant difference between the first and second events, multivariate $F(13,476)=$ 24.61, $p<0.001$. Results of univariate ANOVAs revealed significant differences for each variable, with scores from the small case study session higher on each item than scores for the large introductory event. Factor analysis of data from the introductory event yielded a single factor that accounted for $63.4 \%$ of the variance in the scale. Factor analysis of data from the small group case event also yielded a single factor accounting for $65.9 \%$ of scale variance. Cronbach's alpha revealed a very high internal consistency of 0.951 and 0.952 for the two events, respectively. Conclusions: IPE events can positively increase self-report measures of IPE competencies. The assessment tool used may have measured one overarching construct of collaboration. The tool represents an initial effort toward measurement of each of the four specific competencies, an area in need of refinement. This study demonstrated the impact of IPE events housed within an IPE curriculum.
\end{abstract}

\section{INTRODUCTION}

Healthcare delivery has been undergoing dramatic changes in the past few decades regarding the collaboration necessary to manage the breadth and depth of information required to treat patients. The majority of healthcare visits now entail complex treatment regimens and require multiple professionals to provide optimal care. ${ }^{1}$ Because of the need to communicate among and between professionals, education preparing students for interprofessional collaboration is essential. Different healthcare fields have their own language, set of procedures, and expected ways of interacting. As a result, there has been a significant increase of interest in interprofessional education (IPE). Such education would typically occur for practitioners as part of their continuing professional education. Unfortunately, such education usually occurs along professional demarcations, with individuals attending educational programs with same-profession attendees and content. There has been limited focus and opportunity for 
interprofessional learning at professional conferences, though this appears to be changing recently, with several professional organizations offering continuing education activities at their professional meetings. ${ }^{2-4}$

In addition to experienced professionals being able to work collaboratively across disciplines, there is a need for newly hired healthcare professionals to be able to integrate quickly within the workplace environment. Hence, there is a real need for IPE to take place during university education. Riesen et al found that an interprofessional activity increased student interprofessional competence as evidenced by increases in observer ratings of performance in clinical simulation activities. ${ }^{5}$ There were also concomitant increases in self-perceived changes of one's own interprofessional competence and attitudes towards interprofessional care.

Although the concept of IPE originated in the clinical domain to help professionals learn how to deal with complex patient situations, several reasons exist for its inclusion into the academic training of professionals. ${ }^{6}$ One reason is that health care professionals, who are charged with providing the most efficient and effective patient care, have found that collaborative communication among various professionals is one potential method to meet this goal. ${ }^{7}$ Consistent with this, the Institute of Medicine (IOM) stated that health care professionals communicate best and work most effectively when they gain an understanding of others' roles. ${ }^{8}$ In addition, organizing pre-licensure students into interprofessional groups with the purpose of learning about each other's roles while engaged in a collaborative environment is one potential factor that could aid in increasing readiness for entry-level clinicians to function on an interprofessional team. ${ }^{9,10}$ Finally, recent changes in the health care delivery system are having an impact on expectations of entry-level health science graduates; health care employers now expect entry-level clinicians to use a high level of clinical decision making in a short period of time. ${ }^{11}$

Health Science education programs are introducing the concepts of IPE into their curricula in varying ways and amounts. For example, Brashers et al described their attempts to develop and integrate IPE into their medical and nursing curricula. ${ }^{12}$ They noted that their initiative has increased support for, and interest in, IPE at both the medical and nursing schools as well as in their associated healthcare system. Hamilton suggested that combining interprofessional with cultural competence training could increase interprofessional tolerance and decrease barriers to interprofessional competence. ${ }^{13} \mathrm{Hallin}$ et al evaluated the impact of a clinical teamwork training program in a real world context. ${ }^{14}$ They discovered that students in medicine, occupational therapy, nursing, and physiotherapy who actively participated in the clinical teamwork training program evidenced increases in perceived interprofessional competence, improved knowledge of the other professions involved in client care, clarity of their own roles, and improved communication and teamwork as evidenced by students' answers on questionnaires.

To develop collaborative expertise, it is essential to determine specific competencies required to be an effective interprofessional collaborator and to design activities which develop those skills. ${ }^{15}$ Several recent studies have attempted to identify specific interprofessional competencies required for successful practice among health care providers. ${ }^{16,17} \mathrm{As}$ a result, the Interprofessional Education Collaborative Expert Panel (IPEC) convened and identified four competencies that transcend professional boundaries and are essential for interprofessional functioning; those four competencies are a) values/ethics for interprofessional practice, $b$ ) roles/responsibilities, c) interprofessional communication, and d) teams and teamwork. ${ }^{18} \mathrm{An}$ important next step is assessment of these competencies. Hunter et al utilized a small sample of 21 students from 8 professions (child life studies, medicine, nursing, occupational therapy, pharmacy, physical therapy, radiation sciences, and social work) to assess improvement in competency of students completing a pain interprofessional education placement over a five week period. ${ }^{19}$ Hunter et al found significant increases in IPE competencies as measured by the Interprofessional Care Core Competencies Global Rating Scales. ${ }^{19}$ This represents one attempt to assess the newly established IPE competencies, but additional work with larger sample sizes is needed.

The authors of the current paper have incorporated IPE into their health sciences curricula for the past six years. Students from multiple programs (counseling psychology, nursing, occupational therapy, physical therapy, and physician assistant programs) have attended grand rounds-style presentations and participated in large group programs discussing roles of various providers in patient care and health delivery. The authors recently instituted a comprehensive 2-year curriculum that systematically covers each of the four competencies developed by the Interprofessional Education Collaborative Expert Panel (IPEC). The purpose of this study was to begin to examine impact of the ${ }^{1 \text { st }}$ semester of the curricular program on student self-assessment in interprofessional education.

\section{METHODS}

\section{Participants}

Data was collected from 296 students enrolled in professional educational programs, including counseling psychology, nursing, occupational therapy, physical therapy, and physician assistant, who attended two IPE events as part of course requirements within their programs. The nursing program is a diploma program, physical therapy is a clinical doctorate degree program, and the

(c) The Internet Journal of Allied Health Sciences and Practice, 2016 
remaining three are master's degree programs. All students were in their first professional semester, except for counseling psychology students, whose length of time in the program was variable due to the non-cohort nature of their curriculum. Students were placed into interprofessional groups of 8-10 students per group, with groups comprised of members from each of the participating academic programs to form an interprofessional group.

\section{Interprofessional Events}

Students participated in two interprofessional events.

Introductory event: All students were present at the introductory event, which was an introductory presentation on IPE at the beginning of the fall semester. A speaker with expertise in IPE gave a 45-minute presentation, including the history of IPE, the relevance of working together in teams, and the recently adopted interprofessional competencies. ${ }^{18}$ Students were seated with their assigned groups, and at the conclusion of the presentation, they introduced themselves to the members of their groups. They all provided information about their program of study and other professional information about themselves.

Case study event: Each small group of students participated in a case study event with a faculty facilitator in the fall semester after the introductory event. At the case study event, they participated in a small group case-based experience with the facilitator asking questions to promote discussion about professional roles and responsibilities in the context of a clinical case. All groups used the same clinical case that was developed to include a variety of medical and psychosocial factors to promote contribution by students from all of the health professions. The case involved an individual who was previously a highly esteemed member of the community but had become severely depressed and was drinking heavily following the death of his wife. He was recently admitted to a local medical center's acute care ward following an accident in which he was a pedestrian hit by an automobile. The case included physical status measures, listing of medications, radiographs of his right fractured leg, occupational history, and family and social history. Thus, the case included material relevant to each of the professions that students represented. Students described what they envisioned their roles and responsibilities in the case to be and had a chance to ask questions to help differentiate roles and responsibilities between the professions.

\section{Questionnaire Development}

A 13-item self-report questionnaire using a 10-point Likert scale was developed based on the four competencies of IPE. ${ }^{18}$ The purpose of one of the items was to seek feedback about the value of the event (Question 1) while the purpose of the other questions was to assess the four interprofessional competencies identified by IPEC as related to the event attended: a) values/ethics for interprofessional practice (questions 11, 12, and 13); b) roles/responsibilities (questions 2, 3, and 4); c) interprofessional communication(questions 8, 9, and 10); and d) teams and teamwork (questions 5, 6, and 7).

\section{Data Management and Analysis}

Approval for this human subject's research was obtained from the University Institutional Review Board. Participants completed the questionnaire anonymously at the end of each of the two events. There were 262 out of 296 questionnaires returned from the introductory event and 228 questionnaires from the case study event. Data were secured in a password-protected computer in a locked faculty office. Four subjects had incomplete data on the introductory event questionnaire and were eliminated from all analyses. A one factor Multivariate Analysis of Variance (MANOVA) was performed and was followed by univariate Analyses of Variance with time/event (i.e., post introductory event versus post case study event) as the independent variable with each of the items from the IPE questionnaire as the dependent variables.

In order to examine the structure of the questionnaire, a factor analysis was computed using principal components extraction. Cronbach's alpha was computed to determine internal consistency of the items on the scale. These analyses were performed initially only on data from the introductory event. In order to identify stability of the initial results, subsequent analyses were performed on data from the case study event.

\section{RESULTS}

A one factor Multivariate Analysis of Variance (MANOVA) was computed to compare scores on each of the items of the authordeveloped IPE questionnaire. Results of this analysis (Table 1) revealed a significant difference between the first and second events, multivariate $F(13,476)=24.61, p<0.001$. Results of univariate ANOVAs, with event (first versus second) as the independent variable and each of the items on the scale as the dependent variables, revealed significant differences for each variable, with scores from the case study event higher on each variable than scores for the introductory event.

(C) The Internet Journal of Allied Health Sciences and Practice, 2016 
Table 1. Results of Analysis of Scores on items in the author-developed IPE Questionnaire.

\begin{tabular}{|c|c|c|c|c|}
\hline Item & $\begin{array}{c}\text { Event } 1 \\
\text { Mean } \\
\text { (Standard } \\
\text { Deviation) }\end{array}$ & $\begin{array}{c}\text { Event } 2 \\
\text { Mean } \\
\text { (Standard } \\
\text { Deviation) }\end{array}$ & $F$ & $p$ \\
\hline 1. The event was interesting and held my attention. & $\begin{array}{c}6.61 \\
(2.10)\end{array}$ & $\begin{array}{c}9.05 \\
(1.18)\end{array}$ & 243.04 & .000 \\
\hline $\begin{array}{l}\text { 2. My knowledge of interprofessional education and its } \\
\text { relevance has increased as a result of attending this event. }\end{array}$ & $\begin{array}{l}7.75 \\
(1.90)\end{array}$ & $\begin{array}{l}8.96 \\
(1.31)\end{array}$ & 66.18 & .000 \\
\hline $\begin{array}{l}\text { 3. I have come to an increased understanding and awarenes } \\
\text { of the roles and responsibilities of individuals from } \\
\text { professions other than my own. }\end{array}$ & $\begin{array}{c}7.43 \\
(1.94)\end{array}$ & $\begin{array}{l}8.88 \\
(1.24)\end{array}$ & 93.82 & .000 \\
\hline $\begin{array}{l}\text { 4. This increased understanding will help in assessment } \\
\text { and treatment of patients with whom I will interact. }\end{array}$ & $\begin{array}{c}7.87 \\
(1.89)\end{array}$ & $\begin{array}{c}8.70 \\
(1.51)\end{array}$ & 28.04 & .000 \\
\hline $\begin{array}{l}\text { 5. This event helped increase my comfort in working with } \\
\text { individuals from professions other than my own. }\end{array}$ & $\begin{array}{c}7.61 \\
(1.94))\end{array}$ & $\begin{array}{c}8.60 \\
(1.52)\end{array}$ & 38.41 & .000 \\
\hline $\begin{array}{l}\text { 6. I have gained an increased appreciation for the } \\
\text { importance of interprofessional teamwork when assessing } \\
\text { and treating patients. }\end{array}$ & $\begin{array}{c}8.15 \\
(1.68)\end{array}$ & $\begin{array}{c}9.09 \\
(1.25)\end{array}$ & 47.96 & .000 \\
\hline $\begin{array}{l}\text { 7. I believe I have developed increased ability to } \\
\text { communicate with individuals from professions other than } \\
\text { my own as a result of attending this event. }\end{array}$ & $\begin{array}{c}7.39 \\
(1.95)\end{array}$ & $\begin{array}{c}8.41 \\
(1.54)\end{array}$ & 40.72 & .000 \\
\hline $\begin{array}{l}\text { 8. The communication skills I developed in this event will } \\
\text { help me understand others as well as convey my } \\
\text { knowledge of patients to other professionals. }\end{array}$ & $\begin{array}{c}7.30 \\
(1.93)\end{array}$ & $\begin{array}{c}8.23 \\
(1.68)\end{array}$ & 31.87 & .000 \\
\hline $\begin{array}{l}\text { 9. My interest in interprofessional education has increased } \\
\text { as a result of attending this event. }\end{array}$ & $\begin{array}{c}7.82 \\
(1.91)\end{array}$ & $\begin{array}{c}8.39 \\
(1.74)\end{array}$ & 11.76 & .001 \\
\hline $\begin{array}{l}\text { 10. This event helped me to develop skills that will enable } \\
\text { me to work with professionals from other disciplines in a } \\
\text { manner that conveys mutual respect. }\end{array}$ & $\begin{array}{c}7.39 \\
(1.96)\end{array}$ & $\begin{array}{l}8.54 \\
(1.54)\end{array}$ & 50.21 & .000 \\
\hline $\begin{array}{l}\text { 11. I have come to an increased understanding that } \\
\text { individuals from professions other my own have shared } \\
\text { values with regards to ethical conduct and dignity, rights, } \\
\text { and respect of patients. }\end{array}$ & $\begin{array}{c}7.86 \\
(1.93)\end{array}$ & $\begin{array}{l}8.86 \\
(1.40)\end{array}$ & 41.90 & .000 \\
\hline $\begin{array}{l}\text { 12. I expect my clinical work to improve as a result of } \\
\text { attending this event. }\end{array}$ & $\begin{array}{l}7.91 \\
(2.03)\end{array}$ & $\begin{array}{c}8.49 \\
(1.77)\end{array}$ & 11.14 & .001 \\
\hline $\begin{array}{l}\text { 13. I have come to recognize the importance of } \\
\text { interprofessional education as a result of this event. }\end{array}$ & $\begin{array}{c}8.19 \\
(1.81)\end{array}$ & $\begin{array}{c}8.84 \\
(1.54)\end{array}$ & 17.62 & .000 \\
\hline
\end{tabular}

Results from the initial factor analysis of the introductory event yielded a single factor extracted, based on the criterion of eigenvalues greater than 1 . This one factor accounted for $63.4 \%$ of the variance in the scale. Cronbach's alpha revealed a very high internal consistency of 0.951 . Analysis also revealed that eliminating one question (Question 1 ) would raise Cronbach's alpha to 0.952 . The purpose of Question 1 was to seek feedback about the value of the introductory event while the other questions were intended to measure specific IPE competencies. The factor analysis was subsequently recalculated with Item 1 eliminated from that analysis. That factor analysis yielded one extracted factor that accounted for $65.6 \%$ of scale variance. Elimination of any other item would not have increased alpha at all; in fact, elimination of any item would have reduced Cronbach's alpha, thereby indicating that all remaining items contributed significantly to the overall scale consistency with each other.

The case study event yielded 228 completed questionnaires. A factor analysis was computed on the scale using these 228 participants to determine stability of initial scale analyses. This factor analysis yielded a single factor accounting for $65.9 \%$ of scale variance, very similar to the factor analysis on data from the introductory event. Cronbach's alpha on the data from the case study event was 0.952 , the same as Cronbach's alpha on data from the introductory event. Similar to data from the introductory event, elimination of any item other than question 1 would have decreased Cronbach's alpha. Results on data analysis using data from 
the case study event were completely consistent with analyses on data from the introductory event, thereby indicating a stable factor structure of one factor that is highly internally consistent and consistent over time.

\section{DISCUSSION}

There was a significant difference between the item ratings from after the introductory event to after the case study event with all scores being higher after the case study event. Items reflecting all four of the core competencies were significantly different between the introductory and case study event, not just the roles/responsibilities competency as expected. This finding may indicate enhanced appreciation of interprofessional interactions. A reason for improvement in all competencies may be that there were insufficient items on the questionnaire to distinguish each of the competencies (3 questions per competency); an expanded survey with more items per competency may differentiate between the competencies.

Another reason may be that the case study event actually increased competency in all four areas. At the case study event, roles/responsibilities were an integral part of the discussion, as facilitators instructed students to talk about the patient case from the point of view of their profession. For this reason, it was anticipated that scores on the roles/responsibilities competency would rise.

Increased competency in teams and teamwork may have begun with the establishment of group membership at the introductory event, with each group having their own assigned table. Students introduced themselves to their groups at that event, which could have begun a process of team building. At the case study event, students had the shared task of reaching an organized treatment plan for their "patient," which may have further enhanced their identity as a unique group with a shared purpose that could account for increased competency in teams and teamwork. Both the identification of themselves as a unique group and participation in a united task could account for increased competency in teams and teamwork.

During introductions at the introductory event, students were representing themselves as developing professionals, which may have encouraged more formal and professional communication than would a purely social event or an event with a homogenous group. At the case study event, students had to listen to and speak about matters that directly influenced the care of their "patient." The process of conveying and integrating information may have increased their competency in interprofessional communication through dialogue and exchange.

The patient profile used at the case study event contained elements of substance abuse/dependence, homelessness, access to health care, disability, finances, and family relationships. Discussion of these elements required students to consider and discuss values as well as medical ethical considerations in care organization and delivery. Competency in the area of ethics/values for interprofessional practice may have increased because of this discussion of the patient's situation. Thus, the events may have affected student ratings of all four core competencies.

One other explanation for why there were increases in all four competencies might be the simple passage of time. There was approximately 2 weeks to 2 months between the introductory event and the case study event. Thus, this may simply represent a training effect in students' individual programs of study; it is possible that as students began feeling increasingly competent in their area of study, there was a crossover factor in improving competence in all areas. Although a 2 week to 3 month period of time is relatively short, recent research has shown that improved ratings of competency may occur in as short a period of time as one semester. ${ }^{20}$ Our study did not assess for the potential for a crossover effect, so future research needs to explore if training in one professional program increases both profession-specific and interprofessional competency.

In addition to the hypotheses already provided, it is possible that improvement in all competencies could have been a cumulative effect of both events. Similarly, yet another explanation is that students might have preferred the second, interactive event to the introductory event, which was largely passive learning, and a "halo effect" could have had students increase their ratings of all items. The halo effect is when ratings on one item affect ratings on other items as well. ${ }^{21}$ Participants may have rated themselves high in the area of roles and responsibilities and, as a result of the halo effect, seen themselves as consistently high on all areas. Future research needs to examine ways to obtain competence ratings without risking halo effects.

Future research also needs to evaluate different ways to deliver interprofessional training. A recent study, for instance, used simulations to facilitate development of the interprofessional education competencies among social work and nursing students. ${ }^{22}$ Various training techniques may affect the development of IPE competencies differently.

The IPEC defined interprofessional collaboration as "an active relationship between two or more professional who together with patients to optimize health care that is comprehensive, collaborative, caring, and safe." ${ }^{18} \mathrm{It}$ is possible that the reason all of the

(c) The Internet Journal of Allied Health Sciences and Practice, 2016 
items increased across the two trainings instead of just the roles items is that the items are collectively measuring one general factor of collaboration. Supporting this hypothesis is the factor analysis of our scale revealed one overall factor instead of four separate and distinct factors of the four competencies. Through the two activities, students may have gained an enhanced appreciation of collaboration as a unified construct. It is possible to view the four competencies as components of this construct, where persons of different professions unite in a common goal of excellence in patient care.

One potential confounding factor is that the time from pre to posttest was not constant for all small groups and varied from two weeks to two months. A future study with a constant time interval between events would allow for control of time as a variable, lessening its impact as a confounding factor. Another potential confounding factor was an unequal number of respondents in each event (262 versus 228). It is possible that there was some self-selection in that participants who enjoyed the first event came to the second event but those who did not enjoy the first event, and/or did not enjoy their group or their facilitator, did not attend the second event or did not complete the second questionnaire. Future research needs to utilize matched pairs to evaluate these hypotheses.

The scale used was a self-developed tool, with items related specifically to events and therefore might not be generalizable to other programs that structure their interprofessional curricula differently. However, results from analyses revealed the scale to be consistent both internally and over time, which indicates that its use in IPE could be valuable. Future scale development could focus on the competencies independent of specific educational programs or events.

It may also be important to consider competencies that are unique to specific professions versus those that span across the interprofessional community as well as those that can only be learned in interprofessional activities and to consider several different models and frameworks currently espoused by the professional community (in addition to the IPEC model). ${ }^{22}$ Specifically, the IPEC competencies are four competencies that are consistent across many different professions. However, physician assistant programs generally utilize the medical model and doctoral psychology training programs often utilize either a scientist-practitioner or practitioner-scholar model. ${ }^{23,24}$ These differing models emphasize unique competencies. How the competencies that these models espouse differ from and are similar to the IPEC competencies and their impact on assessment of various competencies needs to be addressed by future research.

Finally, additional items for each competency measured by the tool used in this study could be developed. Although there were a small number of items per competency, one of the strengths of the tool used in this study was its internal consistency. The potential for using this type of assessment, and in particular this tool, is important because of its internal consistency and consistency over time. As interprofessional education continues to be required by multiple health professions, the ability to assess student progress with these competencies is crucial.

\section{REFERENCES}

1. Goreczny AJ. Forging ahead into the 21st century: Issues in rehabilitation. Int J Rehab and Health. 1995;1:1-3.

2. National League for Nursing [Internet]. Washington, DC: The Association; c2015 [cited 2015 October 30]. Available from: http://www.nln.org/calendar/event-details/2016/02/04/default-calendar/the-2016-leadership-conference---interprofessionalpractice-co-creating-transformative-environments.

3. The American Occupational Therapy Association, Inc. [Internet]. The Association; c 2015 [cited 2015 October 30]. Available from: http://www.aota.org/conference-events/pastconferences/2014conference/pre-conference.aspx.

4. American Physical Therapy Association [Internet]. Alexandria, VA: The Association; c2015 [updated 2013 April 22; cited 2015 October 30]. Available from: http://www.apta.org/CSM/Programming/2013/Education/.

5. Riesen E, Morley M, Clendinneng D, Ogilvie S, Ann Murray M. Improving interprofessional competence in undergraduate students using a novel blended learning approach. J Interprof Care. 2012 Jul;26(4):312-8. [PMID: 22559163]

6. Barnsteimer JH, Disch JM, Hall L, Mayer D, Moore SM. Promoting interprofessional education. Nurs Outlook. 2007;55(3):14450. [PMID: 17524802]

7. Committee on Quality Health Care in America. Crossing the Quality Chasm: A New Health System for the 21st Century. Washington, DC: National Academy Press; 2001.

8. Greiner A, Knebel E. (Eds.) Institute of Medicine. Health Professions Education: A Bridge to Quality. Washington, DC: National Academics Press; 2003.

9. Anderson JE, Ateah $\mathrm{C}$, Wener $\mathrm{P}$, et al. Differences in pre-licensure interprofessional learning: Classroom versus practice settings. J Res Interprof Pract Ed. 2011;2.1:3-24.

10. Hoffman SJ, Harnish D. The merit of mandatory interprofessional education for pre-health professional students. Med Teach. 2007;29(8):e235-42. [PMID: 18236267]

(c) The Internet Journal of Allied Health Sciences and Practice, 2016 
11. Frenk J, Chen L, Bhutta ZA, et al. Health professionals for a new century: Transforming education to strengthen health systems in an interdependent world. Lancet. 2010;376(97560;1923-58. DOI: 10.1016/S0140-6736(10)61854-5. [PMID: 21112623]

12. Brashers V, Peterson C, Tullmann D, Schmitt M. The University of Virginia interprofessional education initiative: An approach to integrating competencies into medical and nursing education. J Interprof Care. 2012;26(1):73-5. [PMID: 22233374]

13. Hamilton J. Two birds with one stone: Addressing interprofessional education aims and objectives in health profession curricula through interdisciplinary cultural competency training. Med Teach. 2011;33(4):e199-203. [PMID: 21456978]

14. Hallin $K$, Kiessling A, Waldner A, Henriksson P. Active interprofessional education in a patient based setting increases perceived collaborative and professional competence. Med Teach. 2009;31(2):151-7. [PMID: 18937139]

15. Wilhelmsson M, Pelling S, Uhlin L, Owe Dahlgren L, Faresjo T, Forslund K. How to think about interprofessional competence: A metacognitive model. J Interprof Care. 2012;26(2):85-91. [PMID: 22236489]

16. Conway JF, Little $P$, McMillan M, Fitzgerald M. Determining frameworks for interprofessional education and core competencies through collaborative consultancy: the CARE experience. Contemp Nurs. 2011;38(1-2):160-70. [PMID: 21854247]

17. Sims D. Achieving collaborative competence through interprofessional education. Lessons learned from joint training in learning disability nursing and social work. Soc Work Ed. 2011;30:98-112.

18. Interprofessional Education Collaborative Expert Panel. Core Competencies for Interprofessional Collaborative Practice: Report of an Expert Panel. Washington, D.C.: Interprofessional Education Collaborative; 2011.

19. Hunter JP, Stinson J, Campbell F, Stevens B, Wagner SJ, Simmons B, White M, van Wyk M. A novel pain interprofessional education strategy for trainees: Assessing impact on interprofessional competencies and pediatric pain knowledge. Pain Res Manag. 2015;20(1):e12-20. [PMID: 25144859]

20. Nimmagadda J, Murphy Jl. Using simulations to enhance interprofessional competencies for social work and nursing students. Soc Work Ed. 2014;33:539-48.

21. Keeley JW, English T, Irons J, Henslee AM. Investigating halo and ceiling effects in student evaluations of instruction. Educ Psychol Meas. 2013;73:440-57.

22. Thistlethwaite JE, Forman D, Matthews LR, Rogers GD, Steketee C, Yassine T. Competencies and frameworks in interprofessional education: A comparative analysis. Acad Med. 2014;89(6):869-75. [PMID: 24871237]

23. Carlson JR. Human simulation for physician assistants. In: Wilson L, Rockstraw L, editors. Human Simulation for Nursing and Health Professions. New York: Springer; 2012. p. 293-316.

24. Bell DJ, Hausman EM. Training models in professional psychology doctoral programs. In: Johnson WB, Kaslow NJ, editors. The Oxford Handbook of Education and Training in Professional Psychology. New York: Oxford University Press; 2014. p. $33-51$. 